\title{
Epidemiología del sindrome de Reye
}

Reye's Syndrome in the United States from 1981 through 1997. Belay ED, Bresee JS, Holman RC, et al. N Engl J Med 1999;340:1377-82.

\section{Objetivo}

Describir las características epidemiológicas de los pacientes con sindrome de Reye y la tendencia de los casos reportados por el sistema de vigilancia del sindrome de Reye, desde el $1^{\circ}$ de diciembre de 1980 al 30 de noviembre de 1997

\section{Diseño}

Reportes de casos.

\section{Lugar}

Estados Unidos

\section{Participantes}

1207 casos reportados con sindrome de Reye.

\section{Evaluación de factores de riesgo}

En el análisis de los casos se tuvo en cuenta: la edad, el sexo, la raza, la procedencia, la época del año, el antecedente de enfermedad respiratoria, digestiva, varicela, u otras enfermedades eruptivas y el consumo de salicilatos.

\section{Medición de resultados principales}

Todos los casos fueron identificados a través del sistema de vigilancia del CDC (centro de control de enfermedades), para el sindrome de Reye. Sólo los pacientes menores de 18 años de edad que cumplieron con la definición de caso, fueron incluidos en el análisis estadístico. Se evaluó la asociación entre la raza y la distribución de casos según el grupo de edad; y entre los niveles perceptibles de salicilatos en sangre y el periodo de diagnóstico. Compararon las características de los pacientes y los resultados de laboratorio de aquellos que murieron con los sobrevivientes para identificar factores de riesgo asociados a peor pronóstico, calculando riesgos relativos con un intervalo de confianza del 95\%.

\section{Resultados principales}

Desde diciembre de 1980 a noviembre de 1997, se informaron 1207 casos del sindrome de Reye en pacientes menores de 18 años de edad de los cuales el $93 \%$ eran blancos y el $52 \%$ niñas. El número de casos de síndrome de Reye, disminuyó substancialmente a partir de que se informó la asociación del mismo con el uso de la aspirina; luego de un pico en 1980 de 555 casos informados, no ha habido más de 36 casos por año a partir de 1987. El 93\% de los niños tuvo antecedentes de enfermedades; siendo la más común la enfermedad respiratoria viral (73.4\%); seguida por varicela $(20.8 \%)$; diarrea (14.2\%) y otras eruptivas (5,3\%). El $82 \%$ tenía niveles perceptibles de salicilato en sangre. Se reportaron 355 muertes de 1134 casos de los que se obtuvo un informe final (31.3\%). La proporción de fatalidad de caso fue más alta en niños menores de cinco años de edad (RR 1.8; IC95\% 1.5 a 2.1, $p<0.001$ ), y en aquéllos con un nivel de amonio en suero superior a $45 \mu \mathrm{g} / \mathrm{dl}$ (RR 3.4; IC95\% 1.9 a $6.2, \mathrm{p}<0.001$ ).

\section{Conclusiones}

Desde que en 1980, cuando se informó acerca de la asociación entre el sindrome de Reye y el uso de aspirina durante la enfermedad respiratoria por influenza y la varicela; se ha observado un marcado descenso en el número de casos reportados en EE.UU.

\section{COMENTARIO}

El sindrome de Reye se trata de una severa complicàción neurológica poco frecuente, que puede ocasionar la muerte o dejar secuelas permanentes. Se trata de una enfermedad aguda con un cuadro clínicopatológico de encefalopatía y esteatosis hepática que ocurre casi exclusivamente en chicos. El comienzo del cuadro es precedido por vómitos profusos y grados variables de alteraciones neurológicas, que incluyen cambios de personalidad fluctuantes y deterioro de la conciencia. Cuando la encefalopatía progresa, se observan irritabilidad extrema, agitación, confusión, delirio, y eventualmente coma. Entre las alteraciones metabólicas halladas en los pacientes, se observan niveles de amonio y de transaminasas elevados.

El ejemplo del sindrome de Reye y la aspirina es una buena muestra de cómo se pueden establecer fuertes criterios de causalidad con diseños sencillos y "blandos" como la serie de casos. Ante hallazgos dramáticos; los reportes de casos de Reye (series de casos), aunque no utilizan un grupo de comparación y por lo tanto no cumplen con los requerimientos "duros" que exige la evidencia científica, fueron de utilidad a partir de la década de los 80 en Estados Unidos para provocar un cambio inmediato en el comportamiento médico. Tal es así que se reaLizaron campañas masivas de educación y prevención dirigidas a profesionales de la salud y padres, se identificaron rápidamente los me- dicamentos que contenían salicilatos etiquetándolos con una advertencia a partir de $1986^{1}$. Esto trajo aparejado la sustitución gradual de la aspirina por el paracetamol (acetaminofeno) o ibuprofeno como antipirético para los niños, aunque el uso de la aspirina no ha cesado completamente, y sigue siendo de elección para enfermedades como artritis reumatoidea juvenil y la enfermedad de Kawasaki. Lamentablemente en nuestro país no disponemos de estadísticas de morbilidad respecto a esta afección, como así tampoco de la incidencia anual de influenza y varicela en niños; donde la aspirina es de uso habitual, de venta libre, y se encuentra en numerosos preparados farmacológicos; y donde además las vacunas antiinfluenza y antivaricela, no son de recomendación habital en este grupo etario. Si bien el riesgo absoluto de Reye en la población susceptible es muy bajo, su ocurrencia puede ser claramente evitada si no se utilizan los salicilatos y se los reemplaza por otros antiinflamatorios no esteroides (AINE).

Este reporte nos deja como lección que el ojo clínico de los que descubrieron el aumento de la incidencia de este sindrome, junto con la investigación de los posibles factores desencadenantes; puede provocar grandes cambios en las prácticas de los médicos y pacientes, en la regulación de productos farmacéuticos, en los organismos de salud y en la comunidad en general.

Dra. Nanci Giraudo

Unidad de Medicina Familiar y Preventiva. Hospital Italiano de Buenos Aires. 